\title{
Mitigasi Gempa Mengurangi Korban dan Kehancuran Akibat Goncangan dan Tsunami
}

\author{
Sarwidi
}

\begin{abstract}
Morte than 2/3 of Indonesian provinve tends and potentially toward earthquake. At those area earthquake can happen suddenly. Earthquake can imply disaster or tsunami. To avoid earthquake constitutes something absurd to do, but to prevent or to minimize its impact could be done. At advanced countries people have high consciousness regarding three general steps: before, at the time earthquake happens and after happening earthquake. Meanwhile at developing countries earthquake management be done anplanned so well, so the destruction of this more than those of advanced countries. In this sense, Indonesia should apply planned disaster management so well and consecutively.
\end{abstract}

Kata kunci: gempa, mitigasi dan manajemen bencana

$\mathrm{M}$ enggunakan salah satu sisinya, uang tidak lagi berharga. Negara Indonesia juga mempunyai dua sisi yang tidak dapat dipisahkan. Satu sisi bermuatan kekayaan alamnya, misalnya kesuburan tanah, minyak, hutan, dan aneka tambang. Satu sisi lainnya adalah kekayaan potensi bencana alamnya, antara lain gempa/tsunami, banjir, dan angin ribut. Dengan demikian, pengelolaan harus mencakup dua sisi tersebut, yaitu bagaimana memanfaatkan kekayaan alam secara bijak dan menekan hingga sekecil mungkin dampak bencana.

Gempa berpotensi menjadi bencana melalui: (1) goncangan tanah dan/atau (2) tsunami. Tulisan ini akan memaparkan secara singkat mengenai fenomena gempa dan tsunami, kejadian di Indonesia, serta cara/solusi pengurangan dampaknya. Usaha mitigasi gempa harus dilakukan terus menerus mengingat dalam hal kegempaan, lebih dari 2/3 wilayah Indonesia adalah wilayah yang rawan gempa. ${ }^{t}$

\section{Fenomena Gempa dan Tsunami}

Gempa diartikan sebagai goncangan pijakan yang cukup kuat. Oleh karena pijakan manusia adalah (masih?) di permukaan bumi, maka pengertian gempa biasanya juga berarti gempa bumi. Sebelum adanya jawaban secara ilmiah, manusia sudah mencoba menjawab melalui mitosmitos tentang fenomena gempa bumi dengan ekspresi yang berbeda antara satu kelompok masyarakat dengan kelompok masyarakat lainnya di muka bumi ini.

Sejalan dengan perkembangan peradabannya, manusia telah berhasil mencoba memecahkan misteri gempa bumi dengan pendekatan ilmiah. Secara ilmiah, menurut penyebabnya, gempa dapat dibagi menjadi 4 macam, yaitu gempa meteorik, gempa tanah runtuh, gempa ledakan, gempa 
tektonik. Dari catatan sejarah, gempa yang paling sering menimbulkan bencana terhadap manusia di muka bumi adalah gempa bumi tektonik. Oleh karena itu, istilah gempa yang biasa disebut di kalangan masyarakat berarti gempabumi tektonik.

Teori yang pemah disusun oleh para ahli kegempaan yang meliputi proses kejadian bumi, terjadinya plat tektonik, lapisan bumi, dan gerakan plat tektonik secara singkat dapat dijelaskan berikut ini.

Para ahlipada zaman modem sekarang ini banyak yang setuju, bahwa semula, tata surya berupa gas panas yang berputar. Dengan berjalannya waktu, sebagian dari kelompok gas terlepas dan mendingin membentuk planet-planet, termasuk planet bumi yang kita diami ini. Sampai sekarangpun, bola bumi kita ini masih terdiri dari bahan yang dingin dan yang panas. Bagian yang dingin dan keras terletak di bagian iuar dan semakin ke dalam lapisannya semakin panas dan cair. Proses pendinginan bumi menyebabkan penyusutan lapisan bumi. Oleh karena lapisan bumi tidak homogin, maka penyusutannyapun tidak merata. Dengan demikian, lapisan bumi yang menyusut menjadi retak-retak. Lapisan bumi yang dekat dengan permukaan adalah keras dan peretakan tersebut menyebabkan terjadinya lempengan-lempengan batuan tektonik. Sebuah lempengan tektonikyang berupa batuan keras dapat mempunyai ketebalan hingga $100 \mathrm{~km}$ atau lebih. Karena perputaran bumi dan adanya proses konveksi akibat pemanasan cairan yang lebih dalam, maka lempengen-lempengan tektonik yang keras tersebut tergelincir $\mathrm{di}$ atas lapisan setengah cair dan bergerak sendiri-sendiri.

Lempengan yang bertemu dapat berbenturan satu dengan lainnya (subduksi). Benturan tersebut menyebabkan penumpukan energi. Apabila enegi tertumpuk dan melampaui kekuatan kritis lempengan, maka batuan akan rusak secara tiba-tiba dan energi dilepaskan ke segala penjuru. Energi yang berubah menjadi getaran tanah yang juga disebut gelombang gempa dan merambat ke permukaan bumi tersebut dapat menggoncangkan benda-benda di permukaan bumi. Fenomena inilah yang disebut gempa bumi tektonik. Dengan demikian, lokasi di sekitar pertemuan antara plat tektonik merupakan lokasi potensial sumber gempa.

Pada lempengen tektonik sendiri terdapat retak-retak (sesar) akibat penyusutan dan tegangan pada batuan bumi. Ada sebagian energi akibat tumbukab antar plat tektonik yang tertahan dalam lempengan bumi dan tidak mencapai permukaan bumi. Energi tersebut dapat tertumpuk pada bagian lempengan yang cukup lemah, misalnya pada sesar. Akumulasi energi juga dapat terjadi dan pergeseran pada sesar dapat terjadi akibat sesar tidak mampu menahan akumulasi energi, sehingga energi dapat terlepas secara tiba-tiba dan menimbulkan gempa bumi. Dengan demikian, lokasi di sekitar sesar juga merupakan lokasi potensial sumber gempa.

Tsunami dapat disebabkan oleh gempa, letusan gunung, atau longsoran tebing di dalam laut. Dari catatan sejarah, tsunami lebih banyak disebabkan oleh gempa yang terjadi di lepas pantai. Mekanisme terjadinya tsunami akibat gempa adalah sebagai

' Firmansyah, J. dan M. Irsyam (2000). "Development of Seismic Hazard Map for Indonesia," Lokakarya Nasional: Bangunan Rumah Tinggal Sederhana Tahan Gempa: Evaluasi, Rekomendasi, dan Sosialisasi, yang diselenggarakan oleh Jurusan Teknik Sipil FTSP UII dengan dukungan Lembaga Penelitian UII, CEEDEDS, dan ACRE, di Hotel Quality, Yogyakarta pada tanggal 6 September 2000 . 
berikut. $^{2}$ Kerusakan plat tektonik dan pergerakan vertikal plat tektonik di dasar laut terjadi secara mendadak menimbulkan gempa dan merubah posisi serta bentuk dasar laut. Perubahan posisi dan bentuk dasar laut yang secara mendadak tersebut diikuti oleh perubahan tempat massa air laut secara mendadak pula. Energi disebarkan melaluj air laut dalam bentuk gelombang. Semakin besar kedalaman laut akan semakin tinggi kecepatan penjalaran gelombang tsunami. Semakin besar magnitut gempa (SR) dan semakin besar kedalaman laut di pusat gempa akan memperbesar energi tsunami, memperbesar panjang gelombang, dan memperpanjang periode gelombang.

\section{Peristiwa Gempa dan Tsunami di Indonesia}

Gempabumi mempunyai beberapa karakteristik khusus, diantaranya adalah: ${ }^{3}$

1. umumnya puncak peristiwa terjadi tanpa peringatan yang jelas,

2. terjadi secara mendadak dan mengejutkan, dan

3. wilayah rawan bencana mudah diketahui dan diidentifikasi.

Belajar dari sejarah, gempabumi kuat dapat mengakibatkan hal-hal yang dapat dibagi menjadi 4 kelompok mekanisme besar, yaitu:

1. goncangan-tanah kuat (strong ground shaking),

2. tsunami,

3. kebakaran, dan

4. kegagalan tanah (ground failure).

Akibat dari berbagai mekanisme di atas dapat menyebabkan kehancuran dan kerusakan bangunan serta dapat menelan korban jiwa atau luka-luka. Beberapa kejadian gempa dapat disebutkan berikut ini: ${ }^{4}$ Goncangan tanah yang kuat dan menimbulkan bencana di Indonesia beberapa tahun terakhir antara lain adalah Gempa Papua 1976, 1981, 2002, 2004 (2 kali); Nusa Tenggara 1992, 2004 (2 kali); Sulawesi 1997, 2000, 2005 (2 kali); Sumatera 1994, 1995, 2000, 2004, 2005; Maluku 1999, Jawa 1998, 1999, 2000 (3 kali), 2001 (3 kali), 2003, dan 2005. Peristiwa bencana gempa di luar negeri beberapa tahun ini adalah Turki 1999 dan 2003, Amerika Latin 1999 dan 2001, India 2002, Algeria 2003, Taiwan 1999, serta Iran 2003 dan 2005.

Tsunami mempunyai beberapa karakteristik khusus, diantaranya adalah: ${ }^{5}$

1. kecepatan gelombang tsunami tersebut dapat mencapai $900 \mathrm{~km} / \mathrm{jam}$ dan secara berangsur berkurang hinggga $50 \mathrm{~km} / \mathrm{jam}$ saat menghantam pantai,

2. waktu penjalaran dari pusat gempa menuju pantai tergantung dari jaraknya, untuk kasus Gempa dan TsunamiAceh tanggal 26 Desember waktu tsunami untuk mencapai Pulau Simeulue 20 menit, Banda Aceh 70 menit, Sri

2 Newmark, N. M. dan E. Rosenbiueth (1971). "Fundamentals of Earthquake Engineering," Prentice Hall-lnc, New Jersey. Suhendro, B. (1994). "Bencana Tsunami dan Upaya Penaggulangannya," Majalah Unisia , Univeversitas Islam Indonesia Yogyakarta, No. 23 Tahun XIV Triwulan III tahun 1994, halaman: $7-19$.

${ }^{3}$ Carter, N. W.(1991). "Disaster Management: A Disaster Manager's Handbook," Office of External Relations, Asian Development Bank, PO Box 789, 0980 Manila, Philippines.

${ }^{4}$ Kompas, 1 Januari 2005.

5 Carter, N. W.(1991). "Disaster Management: A Disaster Manager's Handbook," Office of External Relations, Asian Development Bank, PO Box 789, 0980 Manila, Philippines. 
Langka 2 jam, dan Somalia 6 jam,

3. ketinggian air laut di pantai menyusut secara drastis sebelum gelombang tsunami menghantam, dan

4. muatan energi yang sangat besar mengakibatkan hantaman tsunami di pantai dapat sangat merusakkan dan tinggi gelombang dapat mencapai 30 meter.

Tsunami dapat menyebabkan bencana dalam bentuk banjir bandang pantai, penggaraman tanaman pantai, kekurangan air bersih, kerusakan bangunan dan tanaman pantai, serta korban jiwa dan lukaluka. Beberapa perstiwa gempa yang disertai dengan bencana tsunami di Indonesia adalah antara lain. ${ }^{6}$ Pantai Sulawesi 1969 , Nusa Tenggara Barat 1977, Nusa Tenggara Timur 1992, Pantai Jawa Timur 1994, Pantai Utara Papua 1996, Pantai Barat Sumatera Bagian Utara 2002, dan Pantai Aceh dan Sumatera Utara 2004.

\section{Cara Pengurangan Dampak (Mitigasi) Gempa dan Tsunami}

Hampir mustahil mencegah terjadinya gempa dan tsunami, namun manusia dapat berusaha menekan hingga titik seminimum mungkin dampak yang diakibatkannya dengan melakukan manajemen bencana secara bersiklus yang meliputi tahap sebelum bencana, tahap saat terjadi bencana, dan tahap pasca bencana. ${ }^{7}$ Hazard (kerawanan bencana) akan menjadi Bencana (disaster) apabila tidak dikelola dengan baik. Oleh karena itu, dengan skaia sumber bencana yang relatif sama, korban dan kerugian bencana di negara-negara berkembang akan jauh lebih besar dibandingkan di negara-negara maju karena berbeda dalam praktek pengelolaanya.

Pada kasus bencana gempa dan tsunami, beberapa bidang khusus pengelolaan yang perlu diperhatikan meliputi: (1) kerusakan yang berat dan berkala besar menyebabkan pula perlunya segera dilakukannya pencarian dan penyelamatan, serta bantuan obat-obatan dan penampungan sementara dalam skala yang besar pula, (2) masalah politis agar dapat dipinggirkan sementara agar dapat memudahkan akses dan pergerakan bantuan kemanusiaan, (3) kerusakan infra struktur dan gangguan fasilitas pelayanan umum menjadi prioritas untuk segera dipulihkan agar dampaksosial tidak menjadi semakin besar, (4) rekoveri yang mencakup perbaikan dan pembangunan kembali memerlukan energi yang besar dan biaya yang tinggi, serta waktu yang lama, dan (5) kejadian yang relatif jarang menyebabkan kesulitan dalam meningkatkan kepedulian masyarakat dan usaha mitigasi pada saat kondisi normal.

Usaha yang dapat dilakukan dalam mengurangi dampak bencana gempaantara lain adalah (1) pembuatan sonasi gempa, baik secara makro maupun mikro untuk penataan bangunan, (2) pembuatan peraturan perencanaan dan manual bangunan tahan gempa ${ }^{\mathrm{B}}$ dan (3) mening-

${ }^{6}$ Kompas, 1 Januari 2005

${ }^{7}$ Watanabe, M. (2000). "What the Present Disaster Management Missed: When Disaster Management Cycle Falls," Lokakarya Nasional: Bangunan Rumah Tinggal Sederhana Tahan Gempa: Evaluasi, Rekomendasi, dan Sosialisasi, yang diselenggarakan oleh Jurusan Teknik Sipil FTSP UII dengan dukungan Lembaga Penelitian UII, CEEDEDS, dan ACRE, di Hotel Quality, Yogyakarta pada tanggal 6 September 2000.

${ }^{8}$ Boen, T. dan Rekan (2000). "Bencana Gempabumi: Fenomena dan Perbaikan/ Perkuatan Bangunan (Evaluasi Gempa Bengkulu 4 Juni 2000)," Teddy Boen dan Rekan, Jakarta.Sarwidi,...Op-cit. Pribadi, K. S. 
katkan kepedulian masyarakat dan melakukan program-program sosialisasi, ${ }^{9}$ sehingga masyarakat dapat mempersiapkan untuk mengantisipasi bencana yang akan datang.

Usaha yang dapat dilakukan dalam mengurangi dampak bencana tsunami antara lain adalah (1) membuat sistem peringatan dini, (2) pembuatan sonasi tsunami untuk penataan bangunan terhadap posisi pantai dan pembuatan hutan pantai untuk menahan energi tșunami, (3) pembuatan peraturan perencanaan dan manual bangunan tahan tsunami, ${ }^{10}$ dan (4) meningkatkan kepedulian masyarakat dan melakukan program-program sosialisasi, sehingga masyarakat dapat mempersiapkan diri untuk mengantisipasi bencana yang akan datang.

\section{Penutup}

Mengingat resiko kebencanaan gempa dan tsunami di indonesia sangat tinggi, maka dalam jangka panjang manajemen bencana secara bersiklus sangat perlu untuk dilakukan/dibenahi. Sedangkan jangka pendek khusus dalam kasus Gempa dan Tsunami Aceh, hal-hal yang perlu dilakukan adalah (1) mengidentifikasi bangunan yang masih layak untuk digunakan sebagai tambahan fasilitas penampungan sementara, (2) pembuatan zonasi gempa dan tsunami untuk penataan kembali kota, (3) memelihara kepedulian masyarakat akan kehidupannya di wilayah bencana, (4) menegakkan aturan pembuatan bangunan tahan gempa dan bangunan tahan tsunami atau kalau belum dengan aturan formal perlu dibuat manual bangunan tahan gempa" dan tahan tsunami, dan (5) mensosialisasikan peraturan dan manual tersebut kepada masyarakat terlebih-lebih pada msyarakat pelaku konstrukși dan pejabat terkait (sebagaimana yang sudah dilakukan oleh CEEDEDS sejak tahun 2004 dengan melakukan program sosialisasi bangunan tahan gempa (misalnya seperti pada Gambar 1) yang kerjasama dengan fihak luar negeri, pejabat terkait, asosiasi terkait, dan masyarakat pelaku konstruksi, dan (5) kepercayaan dan solidaritas masyarakat yang tinggi dalam penyaluran bantuan bencana merupakan tantangan tersendiri dalam pengelolaan bencana, sehingga selain oleh Jembaga struktur pemerintah, pengawasan harus juga melibatkan masyarakat (perlu adanya semacam Aid Watch atau Assistance Watch yang independent) agar bantuan dapat mencapai sasaran secara efektif.

(2000). "Gempabumi Bengkulu: Belajar dari Kesalahan," Lokakarya Nasional: Analisis Gempabumi Bengkulu: Penanganan Pengungsi dan Manajemen Bantuan Korban Bencana, yang diselenggarakan oleh Pusat Studi Bencana Alam Universitas Gadjah Mada (PSBA UGM) dan IKPMPB Yogyakarta pada tanggal 29 Juli 2000 di Yogyakarta.

${ }^{\circ}$ CEEDEDS (2005). "Pelajaran Dari Kerusakan Bangunan Teknis Akibat GempaGempa Kuat," Diskusi Bulanan CEEDEDS, Kampus FTSP UIl, bulan Januari 2005.

${ }^{10}$ Suhendro, B. (1994). "Bencana Tsunami dan Upaya Penaggulangannya," Majalah Unisia, Univeversitas Islam Indonesia Yogyakarta, No. 23 Tahun XIV Triwulan ill tahun 1994, halaman: $7-19$.

11 CEEDEDS (2005). "Pelajaran Dari Kerusakan Bangunan Teknis Akibat GempaGempa Kuat," Diskusi Bulanan CEEDEDS, Kampus FTSP UII, bulan Januari 2005. 
Topik: Bencana Alam dan Kemanusiaan

\section{Daftar Pustaka}

Boen, T. dan Rekan,2000. "Bencana Gempabumi: Fenomena dan Perbajkan/Perkuatan Bangunan (Evaluasi Gempa Bengkulu 4 Juni 2000)," Teddy Boen dan Rekan, Jakarta

Carter, N. W.1991. "Disaster Management: A Disaster Manager's Handbook," Office of External Relations, Asian Development Bank, PO Box 789, 0980 Manila, Philippines.

CEEDEDS 2005. "Pelajaran Dari Kerusakan Bangunan Teknis Akibat GempaGempa Kuat," Diskusi Bulanan CEEDEDS, Kampus FTSP UII, bulan Januari 2005.

Fauzi,2001. "Earthquake Prone Areas In Indonesia," National Discussion in the 2000 Disasters. Held in UII on January 29, 2001.

Firmansyah, J. dan M. Irsyam,2000. "Development of Seismic Hazard Map for Indonesia," Lokakarya Nasional: Bangunan Rumah Tinggal Sederhana Tahan Gempa: Evaluasi, Rekomendasi, dan Sosialisasi, yang diselenggarakan oleh Jurusan Teknik Sipil FTSP Ull dengan dukungan Lembaga Peneljtian UII, CEEDEDS, dan ACRE, di Hotel Quality, Yogyakarta pada tanggal 6 September 2000.

Kertapati, E. 2000. "Telaah Potensi Zona Sumber Gempabumi di Indonesia," Lokakarya Nasional: Bangunan Rumah Tinggal Sederhana Tahan Gempa: Evaluasi, Rekomendasi, dan
Sosialisasi, yang diselenggarakan oleh Jurusan Teknik Sipil FTSP UIi dengan dukungan Lembaga Penelitian UII, CEEDEDS, dan ACRE, di Hotel Quality, Yogyakarta pada tanggal 6 September 2000.

Pribadi, K. S.2000. "Gempabumi Bengkulu: Belajar dari Kesalahan," Lokakarya Nasional: Analisis Gempabumi Bengkulu: Penanganan Pengungsi dan Manajemen Bantuan Korban Bencaha, yang diselenggarakan oleh Pusat Studi Bencana Alam Universitas Gadjah Mada (PSBA UGM) dan IKPMPB Yogyakarta pada tanggal 29 Juli 2000 di Yogyakarta.

Sarwidi, 2001a. "Upaya Pengurangan Dampak Bencana Gempabumi," Lokakarya Nasional: Pengembangan Sistem Peringatan Dini: Sebagai Upaya Pencegahan dan Pengurangan Dampak Bencana Alam, yang diselenggarakan oleh Palang Merah Indonesia (PMI) yang bekerja sama dengan Pusat Studi Bencana Alam Universitas Gadjah Mada (PSBA UGM) pada tanggal 31 Januari 2001 di Gedung Pusat UGM Yogyakarta.

Sarwidi,2001b. "Lesson from Failure NonEngineered Structures Damaged by Recent Earthquakes in Indonesia", International Workshop held by the IUDMP-ITB Bandung in collaboration with JICA and AARGI, October 2001 in Bali, Indonesia.

Watanabe, M. 2000. "What the Present Disaster Management Missed: When 